\title{
Fast Track Surgery-Minimizing Side Effects of Surgery
}

\author{
Brij B. Agarwal ${ }^{1} \cdot$ Chintamani $^{2,3} \cdot$ Sneh Agarwal $^{3}$
}

Received: 2 February 2016 / Accepted: 2 February 2016 / Published online: 16 February 2016

(C) Association of Surgeons of India 2016

"The person who takes medicine must recover twice, once from the disease and once from the medicine"-William Osler

"Surgery leaves scars not only on the body but mind as well" has been known for long [1]. Human civilization has progressed with paralleled evolution of technology and its application in surgical science. Surgery was once seen merely as a life-saving option. It has progressed from life to limb saving with function preservation and further to being cytoprotective or cyto-preservative [2]. Surgeons have been, used to setting the agenda for defining their own outcomes, enjoying a fiducial relationship with their patients. This therapeutic privilege and the fulcrum of social pedestal occupied by surgeons is undergoing a change in this era of "informed consent" [3]. The social perceptions of surgeons are suspect, given the dichotomy between the choices we make for ourselves and choices we offer to our patients [4]. In addition to "clinical outcome"-based perspective, patient's perceptionbased perspective is gaining currency $[5,6]$. Patient reported outcomes (PROs) are driving the current march of surgical sciences [7]. The PROs are not only addressing the need for

Chintamani

drchintamani7@gmail.com

1 Department of Surgery Ganga Ram Institute, Post Graduate Medical Education Research, New Delhi, India

2 Department of Anatomy, Lady Hardinge Medical College, New Delhi, India

3 VMMC Safdarjang Hospital, New Delhi, India the precision and perfection in clinical outcomes but are bordering at zero tolerance for adverse events, calling at making them "never events" [8,9]. Much of the PRO-related recovery can be defined as the components of postoperative recovery or postoperative convalescence. Postoperative convalescence relates to the patient-reported recovery after the surgeonexpected clinical outcome has been optimized. This is akin to the side effects of medicine alluded to by Sir Osler.

It would not be an exaggeration to call the PRO-based postoperative convalescence as the "side effects of surgery." It is this side effect of surgery which defines the return to normal, for the surgical patient, and determines the final health-related quality of life (HrQoL).

Abdominal surgery in an index area for the surgeon. Abdominal surgery is distinct from other regions in creating an autonomic wound in addition to the somatic wound [10]. The somatic wound innervated by the thoracolumbar nerves works through the posterior column of spinal cord. The effects of this can be clinically controlled by regional blocks, preemptive analgesia, etc. Minimally, invasive surgery has minimized the somatic wound and should have neutralized the impediment to convalescence absolutely. But, the evidence has been to contrary, in a setting of level 1 designed study for colorectal operations [11]. It is therefore the importance of autonomic wound of abdominal surgery that needs to be considered. The peritoneum, a functional and metabolic omnipresent structure in abdomen, conveys sensations through the largest visceral nerve in the body, i.e., vagus, directly to brain through autonomic pathways. It has distinct nociceptors which at times are unresponsive, i.e., "silent nociceptors" which respond only during an insult such as surgery. In addition to inflammatory cascade of somatic wound, this autonomic wound-mediated inflammation has a tremendous capacity for downstream amplification [12]. The complex interplay of somatic and autonomic wound-mediated inflammatory cascade has been in 
focus of scientist studying postoperative convalescence. This understanding has led to a three-decade-old hypothesis that a multimodal intervention to abort the cascade at different levels will lead to enhanced recovery from abdominal surgery [13]. Following this understanding, the concept of minimizing the side effects of surgery or surgical rehabilitation or postoperative convalescence or enhanced recovery after surgery has gained a nomenclature of "fast track surgery" [14]. To ensure success of this understanding, the various stations involved in stress response to surgery need to be understood and physiologically optimized. The systemic responses to the surgical stress as shown in Table 1 are amplified in abdominal surgery due to highly metabolic peritoneal involvement.

In addition to these, the peritoneum, the Teflon of viscera, with an area equaling body surface, and having its own distinct neuro-immuno-humoral axis, projects in a dual manner with spinal as well as vagal afferents [15]. Its inflammatory role, coupled with the diaphragmatic lymphatic pump, provides synergy to the inflammatory cytokine-mediated pathway initiated by the surgical insult. The biomolecular milieu undergoes a volcanic churning involving T cells, B cells, NK cells, complement system, neutrophils, macrophages, mast cells, monocytes, and damaged cells especially mesothelial cells. This leads to a biochemical cascade with numerous cytokines and factors especially TNF- $\alpha$, interleukin (IL)-1, IL-6, and IL-10. It is the understanding of these pathways that has helped us understand the biomolecular basis of surgical convalescence $[16,17]$. These factors are involved in postoperative pain, postoperative orthostatic hemodynamics, postoperative nausea-vomiting complex, postoperative ileus, postoperative coagulation, postoperative fatigue, sleep disturbances, etc. [13]. Postoperative fatigue and sleep disturbances affect the patient's HrQoL for up to 3 month. They have been specifically linked to neuro-immuno-humoral peritoneal axis $[18$, 19]. Based upon this exclusive and unique peritoneal component, specific intraoperative surgical strategies have been recommended as standard guidelines, in the evolving era of minimally invasive practices. These can be summarized [15, 20-23] in Table 2.

The understanding of fast track surgery is undergoing rapid evolution. For its conceptualization for instituted practice,

Table 1 Systems involved in inflammatory response to surgery

\begin{tabular}{ll}
\hline 1. & Autonomic nervous system (autonomic wound mediation) \\
2. & Neurohumoral-endocrine (autonomic wound mediation) \\
3. & Immuno-hematological system \\
& - Acute phase reactants, i.e., CRP \\
• Cytokine pathways/cascades \\
• Neutrophil-lymphocyte interplays \\
• Mature-immature platelet interplays
\end{tabular}

Table 2 General guidelines

1. Avoid handling of tissue unnecessarily

2. Avoid spillage of inflammatory/visceral contents

3. Avoid dry exposure of the tissues

4. Safe and judicious use of surgical energy limited to hemostasis

5. Keeping dissection and hemostasis distinct

6. Avoid introduction of foreign body as far as possible, e.g., starch/ glove powder, threads, and unnecessary free ends of nonabsorbable sutures

7. Cover the raw area with vascular graft, e.g., omentum, peritoneal flap, and broad ligament or falciform ligament

8. Placing the omentum between the wound and viscera

9. Minimizing blood loss

various components as enumerated in Table 3 have to be optimized [13, 24-30]. Based upon this holistic understanding, various guidelines have been formulated for abdominal surgery and especially targeted to colonic surgery, where the rewards of fast track protocols are most needed [31]. These are summarized in Table 4.

Table 3 Different stations for intervention for fast track surgery

\begin{tabular}{ll}
\hline Preoperative & $\begin{array}{l}\text { Preoperative anesthesia/surgical risk evaluation } \\
\text { "Informed consent" to be followed } \\
\text { Goal-directed fluid therapy } \\
\text { Optimization of various organ functions } \\
\text { Abstinence from smoke/alcohol } \\
\text { Evidence-based bowel preparation protocol } \\
\text { Avoid undue prolonged fasting } \\
\text { Goal-directed fluid optimization } \\
\text { Evidence-based use of regional anesthesia/block } \\
\text { Physiological placement of incisions } \\
\text { Use of short-acting opioids } \\
\text { Utilizing minimally invasive surgery to maximum } \\
\text { Evidence-based, procedure-specific opioid } \\
\text { sparing, multimodal analgesia } \\
\text { Evidence-based anti-ileus/anti-emetic prophylaxis } \\
\text { Evidence-based use of drains, tubes, catheters, } \\
\text { and monitors } \\
\text { Evidence-based thrombo-prophylaxis } \\
\text { Early oral nutrition and ambulation } \\
\text { Daily care maps, protocol clinical pathways, } \\
\text { and defined discharge criteria } \\
\text { Evidence-based rehabilitation protocol } \\
\text { Respecting patient's socio-cultural beliefs } \\
\text { Formulating feeding plans according to patient } \\
\text { choices } \\
\text { Incorporating yoga, physiotherapy, and } \\
\text { breathing exercises appropriately } \\
\text { Appropriate antibiotic prophylaxis policy }\end{array}$ \\
\hline Omni-perioperative
\end{tabular}


일

焉

尊

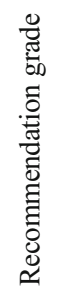

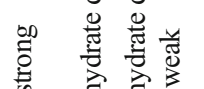

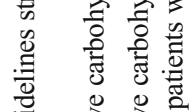

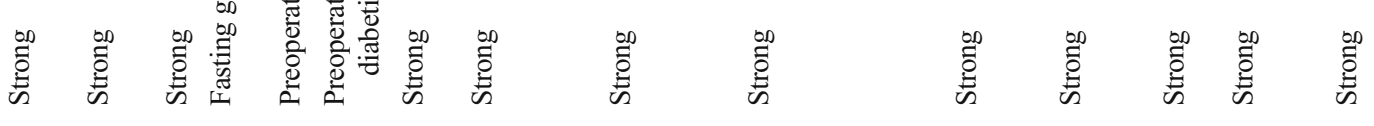

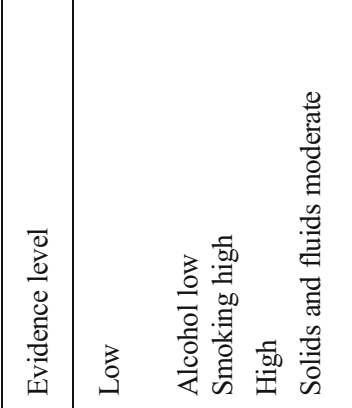

亭

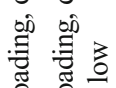

政

突

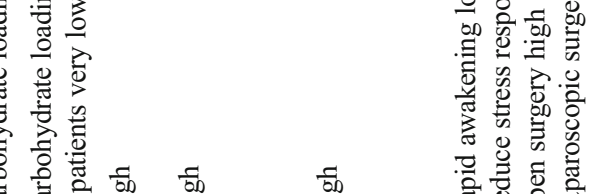

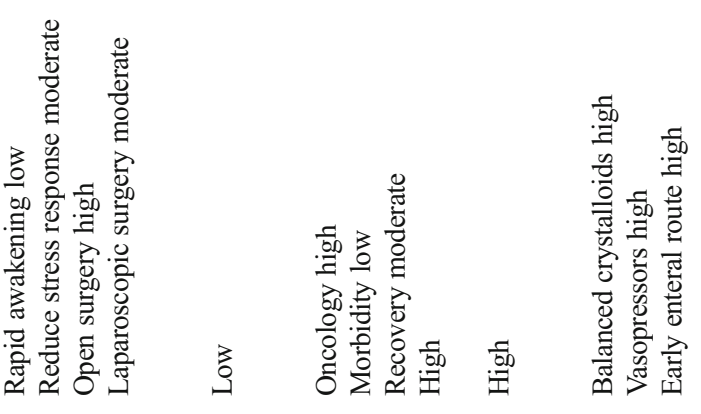

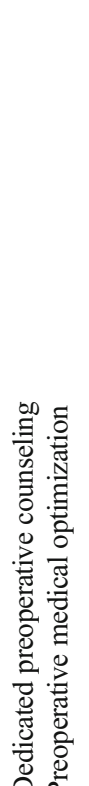

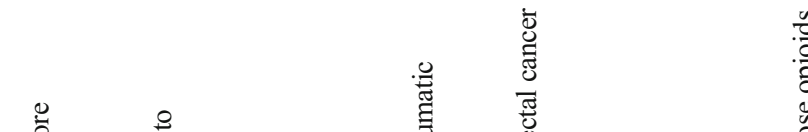

:

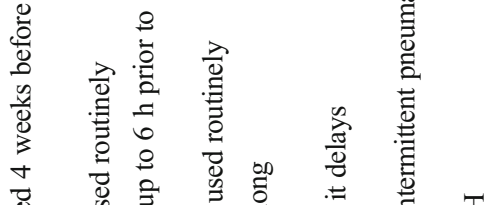

范

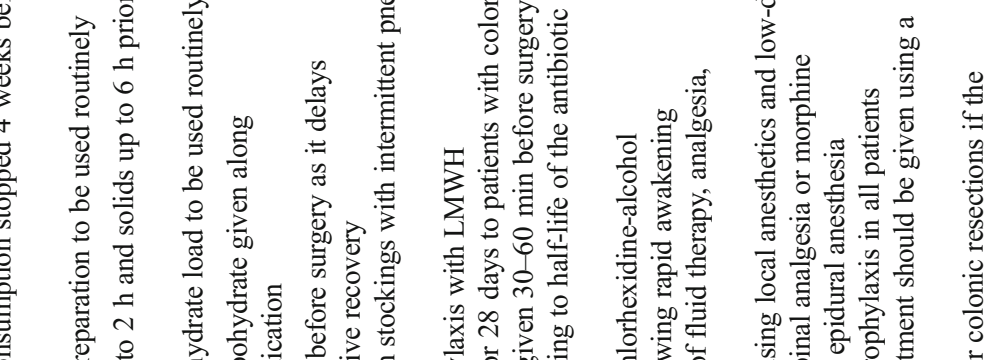

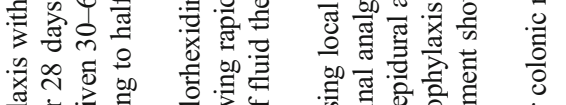

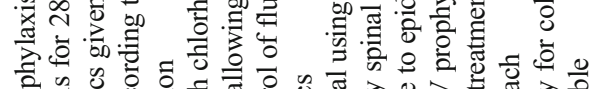

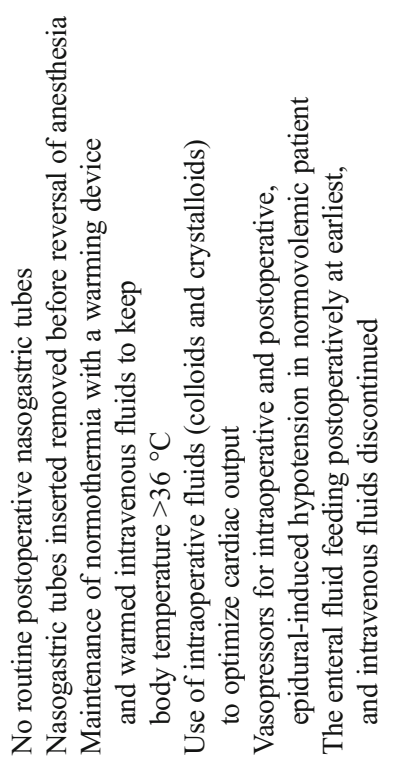

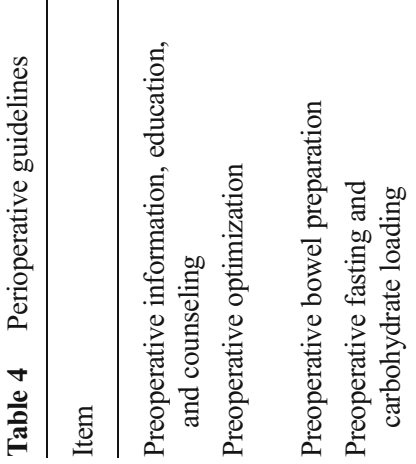

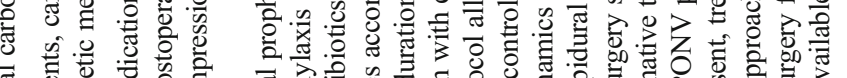

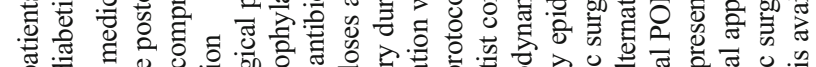

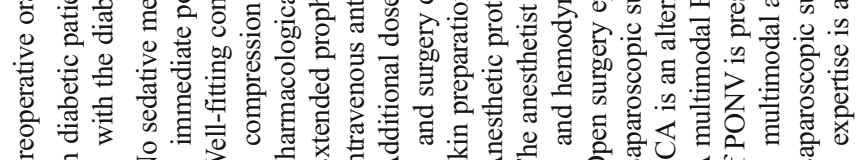

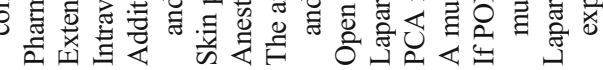

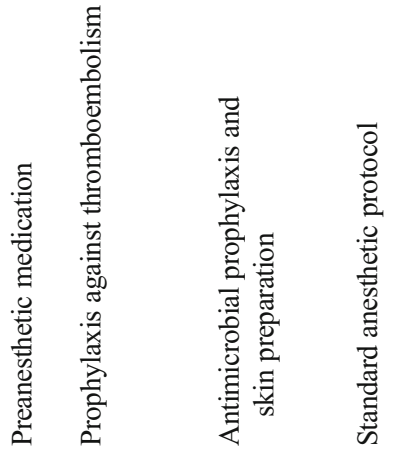

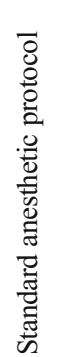

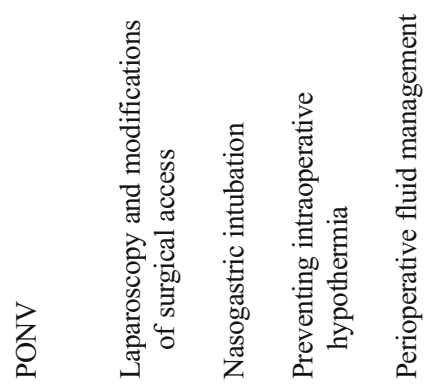




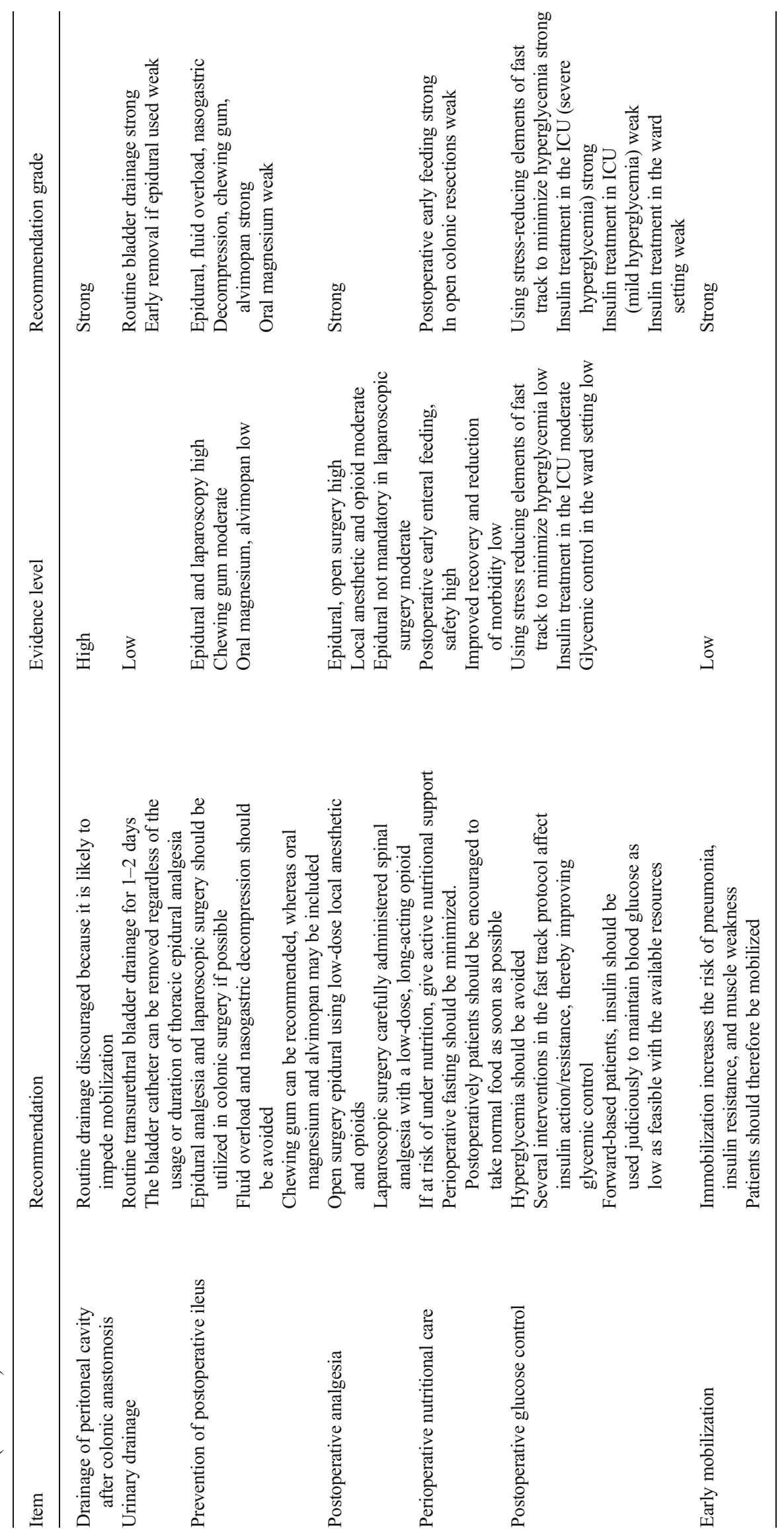


Practice of surgery has largely moved along the evidencebased guidelines. Surgery is also getting protocolled with evidence-based practices. But evidence generation with the existing scientific methodology being premised on RCTs, evidence in surgical practices is also guided by common sense due to challenges in designing adequately powered surgical trials [32-35]. In view of technology-enabled patient, with better or worse information at hand, and given sociopolitical climate of informed consent, a judicious use of guidelines with equal measure of experience-dictated common sense will suffice well for safe surgical practices. Imagineering, the convergence of innovation, molecular understanding, ancient wisdom, genetic sciences, information technology, nanotechnology, and robotic or minimally invasive sciences will be the future of safe surgical practices to minimize the side effects of surgery [36]. In this era of "zero tolerance" to adverse events and enhanced emphasis on PROs, it is necessary that surgical practices were geared towards minimizing the side effects of surgery $[9,27$, 37-39]. This will be a fitting tribute to our founding fathers of surgery [40].

Even with such a comprehensive understanding, new horizons are emerging in our ignorance about postoperative convalescence. A lot of molecular information is changing our current understanding $[17,41]$. Factors as diverse as preoperative gut microbe spectrum and perioperative music have been reported as potential tools towards achieving optimized convalescence $[42,43]$. Achieving an earliest ABCDEF (activity, bath, commitments, diet, exercise, and family life) will be the real test of the efforts to minimize the side effects of surgery [1]. It will require the Imagineering-based understanding with a surgically tailored implementation strategy based on the "knowledge to action" cycle [44].

\section{References}

1. Agarwal BB, Agarwal S, Gupta M, Mahajan K (2008) Transaxillary endoscopic excision of benign breast lumps: a new technique. Surg Endosc 22(2):407-410

2. Agarwal BB, Chintamani, Ali K, Goyal K, Mahajan KC (2012) Innovations in endosurgery - journey into the past of the future: to ride the SILS bandwagon or not? Indian J Surg 74(3):234-241

3. Agarwal BB (2009) Informed consent - "da Vinci code" for our safety in empowered patient's safety. Surg Endosc 23(5):11581160

4. Chintamani, Khandelwal R, Agarwal BB, Ramakant (2012) Current debates in surgery - a cross sectional study amongst Indian surgeons. Indian J Surg 74(3):213-216

5. Agarwal BB (2010) Umbilicus, navel, belly button-vitruvian guide for esthetic cosmetics: a Da Vinci code for beautiful informed consent. Surg Endosc 24(1):236-238

6. Agarwal BB, Sharma S (2010) Geek-speak on "peek port": hybridizing a hybrid technique not Geeks peak. Surg Endosc 24(1):232 233
7. Agarwal BB, Agarwal S (2009) Recurrent laryngeal nerve, phonation and voice preservation - energy devices in thyroid surgery - a note of caution. Langenbeck's Arch Surg 394(5):911-912

8. Agarwal BB, Sarangi R, Mahajan KC (2010) Outcomes with thyroidectomy: what are they? - patient-reported voice quality, not merely nerve preservation. Surg Endosc 24(3):735-737

9. Agarwal BB, Mahajan KC (2010) Laparoscopic biliary tract injury prevention: zero tolerance, error free performance. Surg Endosc 24(3):728-729

10. Kahokehr A, Sammour T, Srinivasa S, Hill AG (2011) Metabolic response to abdominal surgery: the 2-wound model. Surgery 149(3):301-304

11. Basse L, Jakobsen DH, Bardram L, Billesbølle P, Lund C, Mogensen T, Rosenberg J, Kehlet H (2005) Functional recovery after open versus laparoscopic colonic resection: a randomized, blinded study. Ann Surg 241(3):416-423

12. Wu FP, Sietses C, von Blomberg BM, van Leeuwen PA, Meijer S, Cuesta MA (2003) Systemic and peritoneal inflammatory response after laparoscopic or conventional colon resection in cancer patients: a prospective, randomized trial. Dis Colon Rectum 46:147155

13. Kehlet H (2011) Fast-track surgery - an update on physiological care principles to enhance recovery. Langenbeck's Arch Surg 396(5):585-590

14. Mishra AK, Sood J, Agarwal BB (2007) Fast track surgery: current concepts. JIMSA 20(3):243-246

15. Sammour T, Kahokehr A, Soop M, Hill AG (2010) Peritoneal damage: the inflammatory response and clinical implications of the neuro-immuno-humoral axis. World J Surg 34(4):704-720

16. Agarwal BB, Agarwal N, Agarwal KA, Goyal K, Nanvati JD, Manish K, Pandey H, Sharma S, Ali K, Mustafa ST, Gupta MK, Saluja S, Agarwal S (2014) Outcomes of laparoscopic cholecystectomy done with surgical energy versus done without surgical energy: a prospective-randomized control study. Surg Endosc 28(11): 3059-3067

17. Agarwal BB, Nanavati JD, Agarwal N, Sharma N, Agarwal KA, Manish K, Saluja S, Agarwal S (2015) Biomolecular inflammatory response to surgical energy usage in laparoscopic surgery: results of a randomized study. Surg Endosc. doi:10.1007/s0046401544082

18. Sammour T, Kahokehr A, Hill AG (2012) Peritoneal changes due to laparoscopic surgery. Surg Endosc 26(2):587

19. Paddison JS, Booth RJ, Fuchs D, Hill AG (2008) Peritoneal inflammation and fatigue experiences following colorectal surgery: a pilot study. Psychoneuroendocrinology 33:446-454

20. Zargar-Shoshtari K, Sammour T, Kahokehr A, Connolly A, Hill A (2009) Double-blind randomised controlled trial of the influence of dexamethasone on post-operative recovery following colectomy. $\mathrm{Br}$ J Surg 96:1253-1261

21. Menzies D (1992) Peritoneal adhesions. Incidence, cause, and prevention. Surg Annu 24(Pt 1):27-45

22. Ellis H (1971) The cause and prevention of postoperative intraperitoneal adhesions. Surg Gynecol Obstet 133:497

23. Agarwal BB (2010) Energized dissection, energized hemostasis. Arch Surg 145(10):1021

24. Agarwal BB (2010) Yoga and medical sciences. JIMSA 23(2):69 70

25. Agarwal BB (2013) Comment: surgical smoke chemicals include some carcinogens. http://www.medscape.com/viewarticle/809291? nlid $=32627 \_1382 \&$ src $=$ wnl_edit_medn_surg\&spon $=14$

26. Agarwal BB, Sharma S, Gupta MK, Sarangi R, Mahajan KC (2012) Can yoga improve the outcomes of surgery for haemorrhoids? A prospective randomized controlled study. JIMSA 25(1):37-40

27. Agarwal BB, Chintamani C (2011) Reminder of the metrics of endosurgical innovation. Arch Surg 146(9):1108

28. Agarwal BB (2013) Prophylactic antibiotics in surgery. JIMSA 26(4):207 
29. Agarwal KA, Tripathi CD, Agarwal BB, Saluja S (2011) Efficacy of turmeric (curcumin) in pain and postoperative fatigue after laparoscopic cholecystectomy: a double-blind, randomized placebocontrolled study. Surg Endosc 25(12):3805-3810

30. Agarwal BB (2011) Do dietary spices impair the patient-reported outcomes for stapled hemorrhoidopexy? A randomized controlled study. Surg Endosc 25(5):1535-1540

31. Gustafsson UO, Scott MJ, Schwenk W, Demartines N, Roulin D, Francis N, McNaught CE, MacFie J, Liberman AS, Soop M, Hill A, Kennedy RH, Lobo DN, Fearon K, Ljungqvist O, Enhanced Recovery After Surgery Society (2012) Guidelines for perioperative care in elective colonic surgery: Enhanced Recovery After Surgery $\left(\right.$ ERAS $^{\circledR}$ ) Society recommendations. Clin Nutr 31(6): 783-800

32. Agarwal BB, Agarwal KA, Sahu T, Mahajan KC (2010) Traditional polypropylene and lightweight meshes in totally extraperitoneal inguinal herniorrhaphy. Int J Surg 8(1):44-47

33. Agarwal BB (2009) Letter 3: randomized clinical trial of antibiotic therapy versus appendicectomy as primary treatment of acute appendicitis in unselected patients. Br J Surg 96:473-481, Br J Surg. 2009 Oct; $96(10): 1225$

34. Agarwal BB, Agarwal KA, Mahajan KC (2009) Prospective double-blind randomized controlled study comparing heavy- and lightweight polypropylene mesh in totally extraperitoneal repair of inguinal hernia: early results. Surg Endosc 23(2):242-247

35. Agarwal BB, Chintamani, Mahajan KC (2012) Prospective randomized controlled trial to study the safety of a parachute! Quo vadis? Caveamus medicus. Vest deus tecum? JIMSA 25(1):9
36. Agarwal BB (2008) Journey of carbon literate and climate conscious endosurgeon having head, heart, hands, and holistic sense of responsibility. Surg Endosc 22(12):2539-2540

37. Agarwal BB (2010) Inguinal hernia repair - challenges beyond zero recurrence. Saudi J Gastroenterol 16(1):1-2

38. Agarwal BB (2010) Use of ultrasonic shears in thyroidectomy - a note of caution. ANZ J Surg 80:114-115

39. Agarwal BB (2015) Obstructed defecation syndrome. Apollo Med 12(3):175-180

40. Agarwal BB (2015) Krishnan Chand Mahajan. Natl Med J India 28(1):39-40

41. Agarwal BB, Nanavati JD, Agarwal N, Sharma N, Manish K, Saluja S, Agarwal S (2015) Role of energized dissection by the use of surgical energy in the observed functional liver damage during laparoscopic surgery - results of a prospective triple blind randomized study. Curr Med Res Pract 5(3):110-118

42. Friedrich MJ (2015) Unraveling the influence of gut microbes on the mind. JAMA 313(17):1699-1701

43. Hole J, Hirsch M, Ball E, Meads C (2015) Music as an aid for postoperative recovery in adults: a systematic review and metaanalysis. Lancet 386(10004):1659-1671

44. McLeod RS, Aarts MA, Chung F, Eskicioglu C, Forbes SS, Conn LG, McCluskey S, McKenzie M, Morningstar B, Nadler A, Okrainec A, Pearsall EA, Sawyer J, Siddique N, Wood T (2015) Development of an enhanced recovery after surgery guideline and implementation strategy based on the knowledge-to-action cycle. Ann Surg 262(6):1016-1025 